\title{
A Dynamic Model of Demand for Houses and Neighborhoods
}

\begin{tabular}{|c|c|c|c|}
\hline Patrick Bayer & $\begin{array}{l}\text { Robert } \\
\text { McMillan }\end{array}$ & Alvin Murphy & $\begin{array}{c}\text { Christopher } \\
\text { Timmins }\end{array}$ \\
\hline Duke University & University of Toronto & $\begin{array}{l}\text { Washington } \\
\text { University in St. } \\
\text { Louis }\end{array}$ & Duke University \\
\hline
\end{tabular}

July 13,2011

ERID Working Paper Number 107

This paper can be downloaded without charge from

The Social Science Research Network Electronic Paper Collection:

http://ssrn.com/abstract $=1890630$

\section{Economic Research Initiatives at Duke WORKING PAPERS SERIES

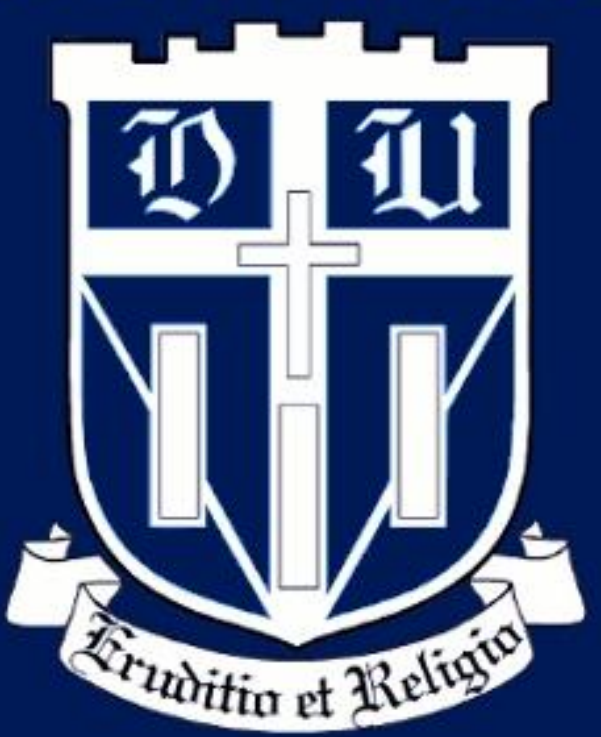




\title{
A Dynamic Model of Demand for Houses and Neighborhoods*
}

\author{
Patrick Bayer, Duke University \\ Robert McMillan, University of Toronto \\ Alvin Murphy, Washington University in St. Louis \\ Christopher Timmins, Duke University
}

July 13, 2011

\begin{abstract}
We develop a tractable model of neighborhood choice in a dynamic setting along with a computationally straightforward estimation approach. This approach uses information about neighborhood choices and the timing of moves to recover moving costs and preferences for dynamically-evolving housing and neighborhood attributes. The model and estimator are potentially applicable to the study of a wide range of dynamic phenomena in housing markets and cities. We focus here on estimating the marginal willingness to pay for non-marketed amenities - neighborhood racial composition, air pollution, and violent crime - using rich dynamic data. Consistent with the time-series properties of each amenity, we find that a static demand model understates willingness to pay to avoid pollution and crime but overstates willingness to pay to live near neighbors of one's own race. These findings have important implications for the class of static housing demand models typically used to value urban amenities.
\end{abstract}

Key Words: Neighborhood Choice, Housing Demand, Hedonic Valuation, Dynamic Discrete Choice

\footnotetext{
${ }^{*}$ We would like to thank Morris Davis, Ed Glaeser, Phil Haile, Aviv Nevo, participants at the Econometric Society Summer Meetings, NBER Summer Institute, Regional Science Annual Meetings, Stanford Institute for Theoretical Economics, Duke's Applied Microeconomics lunch groups, and seminar participants at the University of Arizona, UBC, Georgetown, Minnesota, NYU, Northwestern, Queen's, Rochester, St. Louis Federal Reserve, and Yale for many helpful comments. We also thank Elliot Anenberg for excellent research assistance. All errors are our own.
} 


\section{Introduction}

Models of residential sorting ${ }^{1}$ and hedonic equilibrium ${ }^{2}$ have been the focus of long and active literatures in economics. Many well-known theoretical analyses have combined models of individual location decisions with a market-clearing condition to characterize equilibrium housing prices, household sorting, and public goods provision in an urban setting. Empirical analyses of these models have also been used widely, providing estimates of willingness to pay for a variety of non-marketed local goods (e.g., education, crime, and environmental amenities), estimates of how such amenities are capitalized into local house prices, and also to simulate the impact of policy changes on residential sorting and household welfare. ${ }^{3}$

Despite making progress in many important dimensions, nearly all the models estimated to date in these literatures have adopted a static approach. This has raised a concern - shared by critics and practitioners alike ${ }^{4}$ - that the empirical findings from estimating static models might be subject to serious biases due to the inherently dynamic nature of household location decisions. ${ }^{5}$

That location decisions are dynamic follows from a number of key features of the housing market: (i) large transactions costs that make moves relatively rare, (ii) changing household tastes and needs over the life-cycle, and (iii) evolving local amenities and housing prices that give neighborhoods a dynamic character. Yet estimating truly dynamic models of the location decision is difficult for two primary

\footnotetext{
${ }^{1}$ Theoretical contributions to this literature include papers by Ellickson (1971), Epple, Filimon, and Romer (1984), Epple and Romer (1991), Epple and Romano (1998), and Nechyba (1999, 2000). Empirical contributions include Epple and Sieg (1999), Ferreyra (2007), Bayer, Ferreira, and McMillan (2007), and Kuminoff (2008).

${ }^{2}$ See Rosen (1974), Epple (1987), Ekeland, Heckman, and Nesheim (2004), Bajari and Kahn (2005), Kuminoff and Jarrah (2010), Bishop and Timmins (2010) and the papers discussed therein.

${ }^{3}$ See, for example, Sieg, Smith, Banzhaf, and Walsh (2004), Epple, Romano, and Sieg (2006), and Walsh (2007).

${ }^{4}$ The dynamic nature of location decisions is often acknowledged by the literature and has, for instance, prompted a long-standing debate as to whether all households or just recent movers should be used when estimating preferences for amenities. See the discussion in Kahn (1995), Cragg and Kahn (1997), or Bayer, Keohane, and Timmins (2009).

${ }^{5}$ For example, if households know in a dynamic context that an amenity mean-reverts over time, then a static model is likely to understate household valuations of that amenity, as we discuss below.
} 
reasons. First, estimation of sorting models generally requires the matching of a large sample of households along with their characteristics to the features and location of their housing choices. Given this need, most papers in the previous literature have used data from the decennial Census, which provides great detail about large crosssections of households but very little information about the dynamics of decisionmaking or the evolution of households and neighborhoods. ${ }^{6}$

The second factor that makes estimating dynamic location choice models difficult is the high dimensionality of the state space required in order to characterize the evolution of a system of neighborhoods or cities. Faced with the resulting curse of dimensionality, computing a reasonable dynamic model of residential location decisions that takes account of the heterogeneous and evolving nature of both households and neighborhoods has proved very challenging. More recently, however, a series of technical developments in the literature combined with newly available data have made dynamic estimation in an urban context increasingly feasible.

In this paper, we propose a new method for estimating a dynamic model of demand for houses and neighborhoods. The starting point for our analysis is a unique data set linking information about buyers and sellers to the universe of housing transactions in the San Francisco metropolitan area over a period of 11 years. In addition to precise information about housing structure (e.g., square footage, year built, lot size, transaction price) and house location, a key feature of these data is that they provide important demographic and economic information about the buyers and sellers themselves, permitting us to follow households over time when they move house. ${ }^{7}$

With this data set in hand, we develop a tractable model of neighborhood choice in a dynamic setting, along with a corresponding estimation approach that is compu-

\footnotetext{
${ }^{6}$ Recent papers by Epple, Romano, and Sieg (2010) and Caetano (2010) have made exciting advances in the estimation of dynamic models by using the limited dynamic information in the Census in creative ways. By assuming a stationary environment with respect to neighborhood and population evolutions - assumptions that are very reasonable in the context of the questions they address - these papers take important steps forward in studying issues related to household dynamics over the lifecycle.

${ }^{7}$ Details of the data matching procedure we use are discussed in the next section.
} 
tationally straightforward. This approach, which combines and extends the insights of Rust (1987), Berry (1994), and Hotz and Miller (1993), allows both the observed and unobserved features of each neighborhood to evolve over time in a completely flexible manner. It makes use of information on neighborhood choices and the timing of moves to recover: (i) preferences for housing and neighborhood attributes, (ii) preferences for the performance of housing as a financial asset (e.g., expected appreciation, volatility), and (iii) moving costs.

The model and estimator that we develop build on a number of recent advances in the industrial organization literature on dynamic demand for durable and storable goods. ${ }^{8}$ First, motivated by the fact that housing constitutes two-thirds of the typical homeowner's financial portfolio, we explicitly model housing as an asset and allow each household's wealth to evolve endogenously. Households in our model anticipate selling their homes at some point in the future and thus explicitly consider the expected evolution of neighborhood amenities and housing prices when deciding where and when to purchase or sell their house.

Second, we develop a novel approach for identifying the marginal utility of consumption, which has long been a thorny issue in the literature on demand estimation in applications in both industrial organization and urban economics. The main challenge faced by researchers stems from the strong correlation between a product's price and its unobserved quality, generally requiring instruments that are correlated with price but uncorrelated with unobservables. It is fair to say that such instruments are hard to come by. In our application, we exploit the fact that households face a monetary trade-off both in the standard sense of deciding which product (neighborhood) to purchase but also in the decision of when to move. Here, we take advantage of the fact that realtor fees during our sample period were quite uniform (6 percent of house value) in order to identify the marginal utility of consumption when estimating each resident's move-stay decision.

Thirdly, we relax the index sufficiency assumption that has become a common

\footnotetext{
${ }^{8}$ See Aguirregabiria and Nevo (2010) for an excellent recent review of this literature.
} 
feature of the dynamic demand literature. First proposed by Melnikov (2001) and Hendel and Nevo (2006), this assumption helps to deal with the computational challenges posed by the large state space typically arising in models of dynamic demand. Instead of treating the logit inclusive value as a sufficient statistic for predicting future continuation values, we construct the continuation value from the underlying values associated with each neighborhood in the subsequent period, letting those neighborhood values depend on the current state space in a flexible manner.

We estimate a version of the model that allows for household preference heterogeneity on the basis of race, income, and wealth. We then use the estimated utility parameters to value marginal changes in non-marketed amenities. In particular, we estimate the way that neighborhood racial composition, violent crime, and air pollution affect the flow utility derived from a particular residential choice.

The findings from this exercise indicate that the preference estimates derived from our dynamic approach differ substantially from estimates derived from a comparable static demand model. For example, the per-year willingness to pay to avoid a 10 -percent increase in the number violent crimes per 100,000 population is $\$ 586$ (in 2000 dollars), which is about seventy percent higher than the $\$ 344$ recovered from a comparable static estimation procedure. In the case of air pollution, the corresponding differences are even larger (\$296 from the dynamic model versus $\$ 73$ from the static) though still in the same direction. In contrast, the per-year marginal willingness to pay for race (in particular, the preferences of whites for living in proximity to other whites) is $\$ 1,558$ whereas the estimate from a naive static model is substantially higher at $\$ 1,973$. Given the time-series properties of each of these variables, the sign of the bias from ignoring dynamic considerations accords, in each case, with the intuition that the valuations of mean-reverting amenities will be understated while those of positively-persistent amenities will be overstated by a static model. ${ }^{9}$

\footnotetext{
${ }^{9}$ We develop this reasoning more fully in Section 6 below. In the case of a mean-reverting amenity, for example, a static demand model will incorrectly interpret the justifiable downweighting of a high value of the amenity today by households as a low static valuation, thereby understating willingness-to-pay for the amenity.
} 
Beyond the current application, the model and estimation method that we propose provide a foundation for addressing a wide set of dynamic issues in housing markets and cities. These include, for instance, the analysis of the microdynamics of residential segregation and gentrification within metropolitan areas. ${ }^{10}$ It is worth noting that the estimation approach we develop is computationally light, in addition to which the kinds of transactions data required to estimate the model have become increasingly available for cities throughout the country in recent years, making further exploration of these issues very viable.

The remainder of the paper proceeds as follows: Section 2 describes our data set and the matching procedure used to construct it. Our model, estimation strategy, and parameter estimates are presented in Sections 3 through 5, respectively. Section 6 discusses the implications of estimating a static demand model when agents are actually behaving dynamically; and Section 7 concludes.

\section{Data}

In this section, we describe a new data set that we have assembled, merging information about buyers and sellers with the universe of housing transactions in the San Francisco metropolitan area. We discuss the source data and also demonstrate that the merge results in a high-quality and representative data set based on multiple diagnostic tests.

The data set that we construct is drawn from two main sources. The first comes from Dataquick Information Services, a national real estate data company, and provides information about each housing unit sold in the core counties of the Bay Area (San Francisco, Marin, San Mateo, Alameda, Contra Costa, and Santa Clara) between 1994 and 2004. The buyers' and sellers' names are provided, along with the transaction price, exact street address, square footage, year built, lot size, number of

\footnotetext{
${ }^{10}$ Recent theoretical research on aspects of the dynamic microfoundations of housing markets by Ortalo-Magné and Rady $(2002,2006,2008)$ and Bajari, Benkard, and Krainer (2005) raise a number of additional empirical questions that could be addressed using this framework.
} 
rooms, number of bathrooms, number of units in building, and many other characteristics. ${ }^{11}$ A key feature of this transactions data set is that it also includes information about the buyer's mortgage (including the loan amount and lender's name for all loans). It is this mortgage information which allows us to link the transactions data to information about buyers (and many sellers).

The source of the economic and demographic information about buyers and sellers is the data set on mortgage applications published in accordance with the Home Mortgage Disclosure Act (HMDA), which was enacted by Congress in 1975 and is implemented by the Federal Reserve Board's Regulation C. ${ }^{12}$ The HMDA data provide information on the race, income, and gender of the buyer/applicant, as well as the mortgage loan amount, mortgage lender's name, and the census tract where the property is located.

We merge the two data sets on the basis of the following variables: census tract, loan amount, date, and lender name. Using this procedure, we obtain a unique match for approximately 70 percent of sales. Because the original transactions data set includes the full names of buyers and sellers, we are also able to merge demographic and economic information about sellers into the data set, provided (i) a seller bought another house within the metropolitan area and (ii) a unique match with HMDA was obtained for that house. This procedure allows us to merge in information about sellers for approximately 35-40 percent of our sample.

To ensure that our HMDA/Dataquick matching procedure is valid, we conduct several diagnostic tests. Using public-access Census micro data from IPUMS, we first calculate the distributions of income and race of those who purchased a house in 1999 in each of the six Bay Area counties. We compare these distributions to the

\footnotetext{
${ }^{11} \mathrm{By}$ comparison, the list of housing characteristics is considerably more detailed than that available in Census microdata, for example.

${ }^{12}$ The purpose of the act is "to provide public loan data that can be used to determine whether financial institutions are serving the housing needs of their communities and whether public officials are distributing public-sector investments so as to attract private investment to areas where it is needed." Another purpose is to identify any possible discriminatory lending patterns. (See http://www.ffiec.gov/hmda for more details.)
} 
distributions in our merged data set in Table A.1 in the Appendix. As can be seen, the numbers match almost perfectly in each of the six counties, strongly suggesting that the matched buyers are representative of all new buyers. Table A.2 provides a second diagnostic check, concerning the representativeness of the merged data set in terms of housing characteristics. We report sample statistics for a subset of the houselevel variables taken from the original data set that includes the complete universe of transactions, as well as sample statistics for the merged data set. ${ }^{13}$ A comparison of the two samples suggests that the set of houses for which we have a unique loan record from HMDA is representative of the universe of houses. Overall, our diagnostic checks provide strong evidence supporting the validity of our matching procedure.

In addition to merged data on households and the houses they choose, the estimation routine discussed below also requires that we follow households through time so that we can determine both when they buy and sell a property. Since the data set provides a complete census of all house sales with a unique code for every property, it is straightforward to determine if a household moves. And if an individual buys a house in a given period, we know that he/she will stay there until we see that house sell again. ${ }^{14}$

The unit of geography in the model discussed below is a neighborhood, where we define neighborhoods by merging nearby census tracts until there are approximately 10,000 housing units in each neighborhood. ${ }^{15}$ We drop a number of neighborhoods

\footnotetext{
${ }^{13}$ We drop outlying observations where reported sales price - reported in 2000 dollars - is above the 99th or below the 1st percentile of sales prices. We also drop houses with reported values of lot size, square footage, number of bedrooms, and number of rooms higher (or lower) than their respective maximum (or minimum) reported in Table A.1.

${ }^{14}$ More difficult is determining where a household moves conditional on moving. The raw data do not provide a unique household identifier; however, they do provide the name of both the purchaser and the seller. We use the name information to create a household identifier by looking for a house purchase in a window of time around a sale for which the purchaser's name (in the purchase) matches the seller's name (in the sale). If we cannot find a new purchase within a year on either side of the sale, we assume that the household has either left the Bay Area or moved to a rental unit.

${ }^{15}$ The merging algorithm starts with the least populated census tract, and merges it together with the nearest tract such that the combined population does not exceed 25,000. The algorithm iterates until no possible combination of tracts would result in combined populations of less than 25,000. A population of 25,000 roughly corresponds to 10,000 housing units. The population and geographic data for each census tract come from the 2000 Census.
} 
that have less than 6 sales in any year between 1994 and $2004,{ }^{16}$ leaving us with 225

neighborhoods in total. The corresponding neighborhood boundaries are shown in Figure 1, along with the county names.

Table 1 presents summary statistics for the merged data that we use for estimation. We include summary statistics for both household and neighborhood characteristics.

Table 1: Summary Statistics

Household Characteristics

\begin{tabular}{llllll}
\hline \hline Variable & Obs. & Mean & Std. Dev. & Min. & Max. \\
\hline Income & 263469 & 133.26 & 137.22 & 0 & 11248.08 \\
Down Payment & 263469 & 119.08 & 132.37 & 0 & 2417.18 \\
Sale Price & 263469 & 448.26 & 269.40 & 101.24 & 2691.45 \\
White & 263469 & 1 & 0 & 1 & 1 \\
Year & 263469 & 1999.11 & 3.14 & 1994 & 2004 \\
\hline \multicolumn{5}{r}{} \\
& Neighborhood Characteristics & \\
\hline \hline Variable & Obs. & Mean & Std. Dev. & Min. & Max. \\
\hline Percent White & 2475 & 69.34 & 16.50 & 20.12 & 96.77 \\
Violent Crime & 2475 & 458.62 & 257.37 & 46.03 & 2156.00 \\
Ozone & 2475 & 2.19 & 2.57 & 0.002 & 18.25 \\
Sale Price & 2475 & 428.91 & 210.74 & 117.50 & 1859.31 \\
\hline
\end{tabular}

Note: Income, Down Payment, and Sale Price are measured in $\$ 1000$ 's.

Our household sample consists of over 263 thousand observations. The householdlevel characteristics we focus on are income, race, and wealth. The sample mean household income is around $\$ 133,000$, with a standard deviation of a similar amount. As income is only observed when a household makes a purchase, we assume that income does not change over time. In terms of race, we only use white households when estimating the model, as discussed below; white households account for around 68 percent of households in the Bay Area. Household wealth is measured as the difference between the household's current house value and the initial mortgage amount, with current house value being defined as sales price in the year the house is sold and

\footnotetext{
${ }^{16}$ We drop 28 neighborhoods, equivalent to 11 percent of neighborhoods but only 4 percent of sales.
} 
an imputed price in subsequent years. The imputation uses the original house price and adjusts this according to an appreciation index generated from a repeat sales analysis, with the appreciation index calculated separately for each neighborhood.

The neighborhood characteristics we use are mean house price, air quality (groundlevel ozone concentrations), violent crime rates, and the racial composition (percentage white) of home owners. We control for changing attributes of the houses that sold when calculating time variation in each neighborhood's mean price. ${ }^{17}$ In terms of air quality, we use annual data from the California Air Resources Board (www.arb.ca.gov/adam/) that reports readings from thirty seven monitors in the Bay Area between 1994-2004. While several different measures of ground-level ozone pollution are reported in these data, we use information on the number of days each year that pollution exceeded the one-hour state standard (i.e., 90 parts per billion) to construct specific measures for each neighborhood centroid. In particular, we use the latitudes and longitudes of all monitors to construct a distance-weighted average of the number of 'exceedances' for each neighborhood.

Ozone is a convenient environmental disamenity to study in this context. Unlike many other pollutants, geography and weather are largely responsible for crosssectional variation in ground-level ozone pollution. San Francisco, Oakland, and San Jose all face heavy traffic congestion. However, wind patterns mitigate much of the ozone pollution in San Francisco and Oakland, while worsening it in San Jose; and mountains ringing the southern end of the Bay Area block air flows and contribute to this effect. ${ }^{18}$ At the same time, fog (which is especially prevalent in San Francisco) can lower temperatures and block sunlight, preventing the formation of ozone.

In addition to the cross-sectional variation just described, there is also significant

\footnotetext{
${ }^{17}$ To generate appreciation trends, we use the same repeat sales analysis used to impute individual house values. We regress log price on year and house dummies and create appreciation measures from the coefficients on the year dummies: the regressions and associated appreciation measures are estimated separately for every neighborhood. This procedure is effectively a simplification of the method described in Case and Shiller (1989). The cross-sectional variation in house prices is driven by differences in prices across neighborhoods averaged over all years.

${ }^{18}$ The mountains on the eastern side of the Bay are similarly responsible for high levels of pollution along the I-680 corridor in eastern Contra Costa and Alameda counties.
} 
variation in ozone pollution levels over time, much of which is due to a variety of programs initiated after California passed its Clean Air Act of 1988. Following several years of relatively low ozone pollution, the Bay Area experienced its worst year of air quality for a decade in 1995. In 1996, the vehicle Buyback Program for cars manufactured in 1975 or before was implemented, and this program contributed to the summer of 1997 being the cleanest season since the early 1960's. ${ }^{19}$ While 1998 saw considerably more ozone pollution, the remaining years of our sample returned to relatively low levels. There is no reason to expect that any of these programs would have had special economic consequences for housing prices in any specific part of the Bay Area, aside from those operating through changing amenity values.

Data on violent crimes are taken from the RAND California data base. ${ }^{20}$ These figures represent the number of "crimes against people, including homicide, forcible rape, robbery, and aggravated assault" per 100,000 residents and are organized by city. The data describe crime rates for 80 cities in the Bay Area between 1986 and 2008; and we impute crime rates at the centroid of each neighborhood using a distanceweighted average of the crime rate in each city. We focus our attention on violent (as opposed to property) crimes as they are likely to be less subject to reporting error (see Gibbons (2004)). With that in mind, it is possible that our measure of crime will, to some extent, proxy for other sorts of crimes as well.

Crime rates in the Bay Area (and in many other parts of the US) fell dramatically over the course of the 1990's. In the Bay Area, this is particularly evident in communities starting out with very high rates of violent crime (e.g., East Palo Alto), whereas low crime areas (e.g., Palo Alto) saw virtually no change in crime rates over the decade. In general, however, local crime rates have tended to fluctuate in the short run (annually), and even over longer periods.

The time-series variation in amenities just described may give rise to biases in static demand estimation, anticipating the application in Section 6. Both ground-level

\footnotetext{
${ }^{19}$ Also relevant were the Lawn Mower Buyback and Clean Air Plan of 1997.

${ }^{20} \mathrm{http}: / /$ ca.rand.org/stats/community/crimerate.html
} 
ozone and crime vary a great deal from year-to-year and mean-revert over very short time horizons. Neighborhood racial composition, in contrast, is positively persistent, with any change in composition today likely to persist into the future. If households anticipate either the mean reversion or the persistence, their responses will reflect not only the current change but also those expectations; and as a result, we would expect a static model to return biased estimates when valuing these amenities. Regressions exploring the time-series patterns of each (dis)amenity are shown in Table A.3 in the Appendix.

Figure 1: Appreciation rates by neighborhood

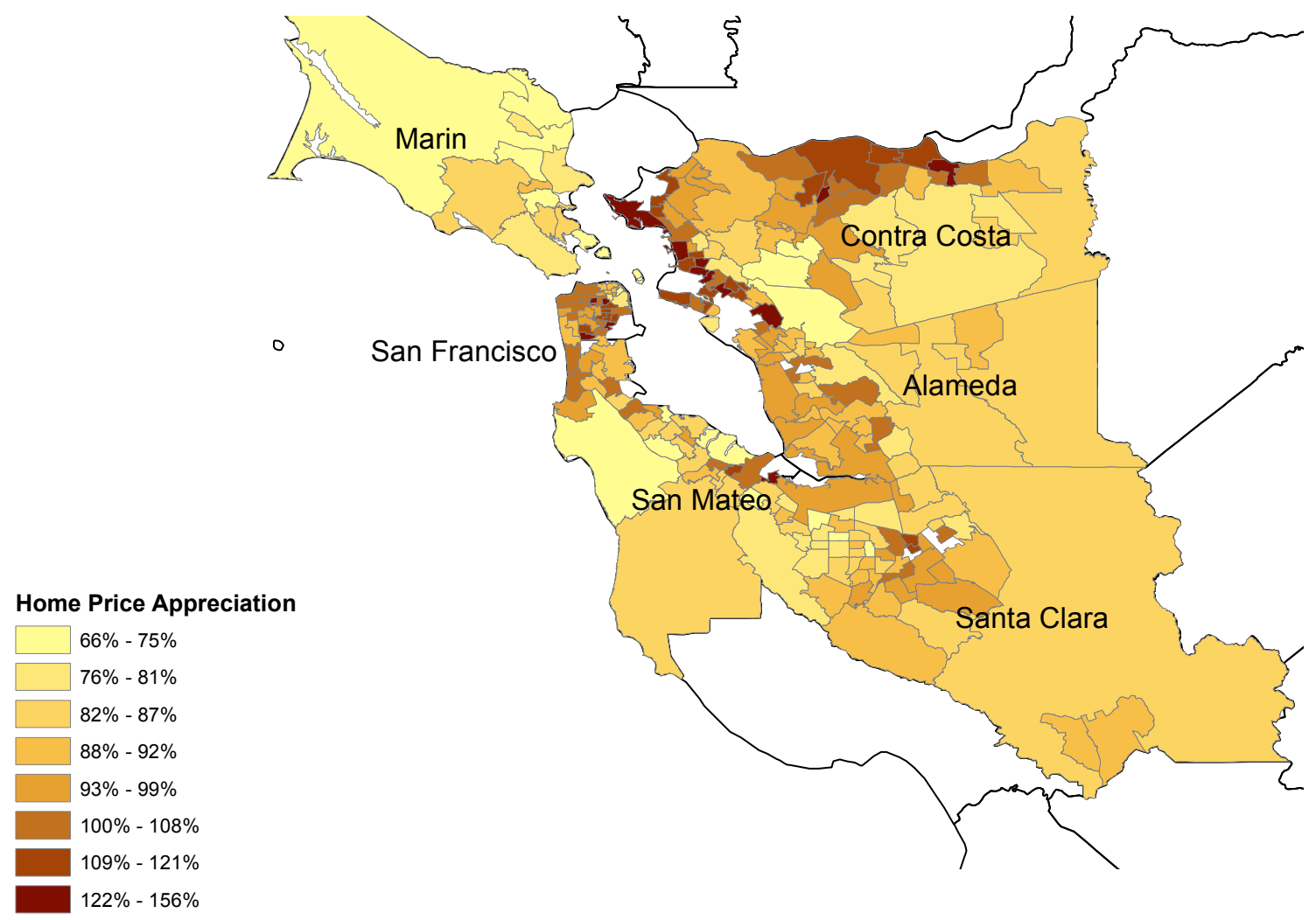

The precision of our model depends critically on the fact that rates of change in amenities and house prices are not uniform across neighborhoods. To illustrate the variation in the evolution of prices across regions of the Bay Area, Figure 1 shows real house price appreciation by neighborhood from 1994 to 2004. The estimated price 
levels are derived separately for each neighborhood using a repeat sales analysis in which the log of the sales price (in 2000 dollars) is regressed on a set of year fixed effects as well as house fixed effects. The figure makes clear the significant differences across neighborhoods in real house price growth over this time period. ${ }^{21}$

\section{A Dynamic Model of Neighborhood Choice}

Previous research modeling the process of household sorting across neighborhoods has generally assumed a static environment. ${ }^{22}$ In developing a dynamic sorting model, we introduce the dynamics of the neighborhood choice problem through two channels: wealth accumulation and moving costs. Households have expectations about the appreciation of housing prices and may rationally choose a neighborhood that offers lower current period utility in return for the increase in wealth associated with house price appreciation in that neighborhood. Moving costs are the other component of the neighborhood choice problem that induce forward-looking behavior. Because households typically pay six percent of the value of their house in real estate agent fees, in addition to the non-financial costs of moving, it is prohibitively costly to reoptimize every period. As a result, households will naturally consider expectations about future utility streams when deciding where to live, making trade-offs between current and future neighborhood attributes and therefore choosing neighborhoods based in part on demographic or economic trends.

The model we present is one of homeowner behavior. ${ }^{23}$ Households are treated as making a sequence of location decisions that maximize the discounted sum of expected

\footnotetext{
${ }^{21}$ Omitted neighborhoods in the study area are shaded white, as are the bordering counties.

${ }^{22}$ See Epple and Sieg (1999), Ekeland, Heckman, and Nesheim (2004), Bajari and Kahn (2005), Ferreyra (2007), and Bayer, McMillan, and Rueben (2011) for several recent examples. Three exceptions are Kennan and Walker (2011) and Bishop (2007), who analyze interregional migration in the US in a dynamic context, and Murphy (2007), who examines the role of dynamic behavior in the supply of new housing.

${ }^{23}$ We do not explicitly model the decision whether to rent or to own. We do, however, include an outside option that includes moving from home ownership in the Bay Area to either a rental property or a home outside the Bay Area.
} 
per-period utilities: formulated in a familiar dynamic programming setup, a Bellman equation captures the determinants of the optimal choice.

In each period, every household chooses whether or not to move. If a household moves, it incurs a moving cost and then chooses the neighborhood that yields the highest expected lifetime utility. The decision variable, $d_{i, t}$, denotes both of the choices made by household $i$ in period $t$, namely (i) the decision of whether or not to move and (ii) the decision of where to move, if the household has decided to move. If a household decides to move, we denote that decision by $d_{i, t}=j \in\{0,1, \ldots, J\}$, where $j$ indexes neighborhoods, $J$ denotes the total number of neighborhoods in the Bay Area and 0 denotes the outside option. If a household decides not to move, we denote this decision by $d_{i, t}=J+1 .^{24}$

The observed state variables at time $t$ are $X_{j, t}, Z_{i, t}$, and $h_{i, t} . X_{j, t}$ is a vector of characteristics of the different neighborhoods that affect the per-period utility a household may receive from living in neighborhood $j \in\{0,1, \ldots, J\}$. For example, $X_{j, t}$ may include variables such as the price of housing and the quality of local attributes such as air quality, crime, or the neighborhood's racial composition. $Z_{i, t}$ is a vector of characteristics of each household that potentially determine the per-period utility from living in a particular neighborhood, as well as the costs associated with moving. This vector may include such variables as income, wealth, or race. And $h_{i, t} \in\{0,1, \ldots, J\}$ denotes the neighborhood chosen in $t-1$, including the outside option.

In addition to the decision variable, $d_{i, t}$, and the observable variables, $X_{j, t}, Z_{i, t}$, and $h_{i, t}$, there are two unobservable variables, $\xi_{j, t}$, and $\epsilon_{i, j, t}$. Of these, $\xi_{j, t}$ represents unobserved neighborhood quality, ${ }^{25}$ and $\epsilon_{i, j, t}$ is an idiosyncratic stochastic shock that

\footnotetext{
${ }^{24}$ The number of choice options is therefore $\mathrm{J}+2$. For a household who lived in neighborhood $j$ in $t-1$, we distinguish between the choices of not moving $\left(d_{i, t}=J+1\right)$ and of moving to a different house within neighborhood $j\left(d_{i, t}=j\right)$, as there are a small number of observations for which households make such within-neighborhood moves. To simplify notation, we do not use a separate index for neighborhoods and choices. For choices $j \in\{0,1, \ldots, J\}$, the household is choosing to move to neighborhood $j$. For choice $j=J+1$, the household is choosing to not move and so to remain in the current neighborhood, which is in $\{0,1, \ldots, J\}$.

${ }^{25}$ We allow households to derive different levels of utility based on their observable demographic
} 
determines the utility a household receives from choosing option $j \in\{0,1, \ldots, J+1\}$ in period $t .^{26}$ Let $s_{i, t}$ denote the states $Z_{i, t}, X_{t}$ and $\xi_{t}$, as well as any other information set variables, such as lagged characteristics, that help predict future neighborhood or household characteristics.

The primitives of the model are $(u, M C, q, \beta)$. Taking these in turn, $u_{i, j, t}=$ $u\left(X_{j, t}, \xi_{j, t}, Z_{i, t}, \epsilon_{i, j, t}\right)$ is the per-period utility function, excluding any moving costs, that household $i$ receives from living in neighborhood $j . M C_{i, t}=M C\left(Z_{i, t}, X_{h_{i, t}}\right)$ is the per-period moving cost function, which is only paid when a household moves. By assumption, moving costs are not a function of where within the metropolitan area the household moves to; however, they are assumed to be a function of the characteristics, $X_{h_{i, t}}$, of the neighborhood the household is leaving in order to capture the fact that realtor fees are proportional to the value of the house one sells. The full flow utility function is given by $u_{i, j, t}^{M C}=u_{i, j, t}-M C_{i, t} I_{[j \neq J+1]}$. The transition probabilities of the observables and unobservables are assumed to be Markovian and are given by $q=q\left(s_{i, t+1}, h_{i, t+1}, \epsilon_{i, t+1} \mid s_{i, t}, h_{i, t}, \epsilon_{i, t}, d_{i, t}\right)$. Finally, $\beta$ is the discount factor.

Each household is assumed to behave optimally in the sense that its actions are taken to maximize lifetime expected utility. That is, the problem of the household is to make a sequence of residential location decisions, $\left\{d_{i, t}\right\}$, to maximize

$$
E\left[\sum_{r=t}^{T} \beta^{r-t}\left(u^{M C}\left(X_{j, r}, \xi_{j, r}, Z_{i, r}, \epsilon_{i, j, r}, X_{d_{i, r-1}, r}\right)\right) \mid s_{i, t}, h_{i, t}, \epsilon_{i, t}, d_{i, t}\right]
$$

The optimal decision rule is given by $d^{*}$, which under the Markov structure of the problem is only a function of the state variables. That is, $d_{i, t}=d_{i, t}^{*}\left(s_{i, t}, h_{i, t}, \epsilon_{i, t}\right)$. When the sequence of decisions, $\left\{d_{i, t}\right\}$, is determined according to the optimal decision rule, $d^{*}$, lifetime expected utility can be represented by the value function. We can

characteristics. In so doing, we differ from previous work, such as Berry, Levinsohn, and Pakes (1995), that forces all individuals to have the same preferences for the unobserved choice characteristic.

${ }^{26}$ As the vector of idiosyncratic shocks contains $J+2$ elements, a household that moves but chooses to reside in the same neighborhood would receive a different draw for $\epsilon$ than if that household chose not to move. 
break out the lifetime sum into the flow utility at time $t$ and the expected sum of flow utilities from time $t+1$ onwards. This allows us to use the Bellman equation to express the value function at time $t$ as the maximum of the sum of flow utility at time $t$ and the discounted value function at time $t+1$. We assume that the problem has an infinite horizon, allowing us to drop the time subscripts on $V$, the value function: ${ }^{27}$

$$
V\left(s_{i, t}, h_{i, t}, \epsilon_{i, t}\right)=\max _{j}\left\{u_{i, j, t}^{M C}+\beta E\left[V\left(s_{i, t+1}, h_{i, t+1}, \epsilon_{i, t+1}\right) \mid s_{i, t}, h_{i, t}, \epsilon_{i, t}, d_{i, t}=j\right]\right\}
$$

Under certain technical assumptions, equation (2) is a contraction mapping in $V$. However, the difficulty is that $V$ is a function of both the observed and unobserved state variables. Therefore, we make a series of assumptions similar to those in Rust (1987) in order to simplify the model.

Assumption (AS): Additive Separability. We assume that the per-period utility function, $u$, is additively separable in the idiosyncratic error term, $\epsilon_{i, j, t}$. Thus we can express the full flow utility function, $u_{i, j, t}^{M C}$, as

$$
u_{i, j, t}^{M C}=u\left(X_{j, t}, \xi_{j, t}, Z_{i, t}\right)-M C\left(Z_{i, t}, X_{h_{i, t}}\right) I_{[j \neq J+1]}+\epsilon_{i, j, t}
$$

Assumption (CI): Conditional Independence. We make the following assumptions regarding the transition probabilities of the observed and unobserved states. The idiosyncratic choice-specific error term, $\epsilon_{i, j, t}$, is distributed i.i.d. Type 1 Extreme value (with density $q_{\epsilon}$ ). Additionally, we assume that conditional on $s_{i, t}$ and $d_{i, t}$, the errors $\epsilon_{i, j, t}$ have no predictive power regarding future states $s_{i, t+1}$ or $h_{i, t+1}$. Based on the structure of the model and the assumption about $\epsilon_{i, j, t}$, it follows that, conditional on $s_{i, t}$ and $d_{i, t}$, the neighborhood chosen in the previous period, $h_{i, t}$, has no predictive power regarding any future states and that $d_{i, t}$ is sufficient to predict $h_{i, t+1}$ perfectly.

\footnotetext{
${ }^{27}$ Assuming an infinite horizon implies that $V_{t}\left(s_{i, t}, h_{i, t}, \epsilon_{i, t}\right)=V\left(s_{i, t}, h_{i, t}, \epsilon_{i, t}\right)$ and $d_{t}\left(s_{i, t}, h_{i, t}, \epsilon_{i, t}\right)=d\left(s_{i, t}, h_{i, t}, \epsilon_{i, t}\right)$.
} 
We can therefore express the transition density for the Markov process, $q$, as ${ }^{28}$

$$
q\left(s_{i, t+1}, h_{i, t+1}, \epsilon_{i, t+1} \mid s_{i, t}, h_{i, t}, \epsilon_{i, t}, d_{i, t}\right)=q_{s}\left(s_{i, t+1} \mid s_{i, t}, d_{i, t}\right) q_{h}\left(h_{i, t+1} \mid d_{i, t}\right) q_{\epsilon}\left(\epsilon_{i, t+1}\right)
$$

This allows us to define the choice-specific value function, $v_{j}^{M C}\left(s_{i, t}, h_{i, t}\right)$, as

$$
v_{j}^{M C}\left(s_{i, t}, h_{i, t}\right)=u_{i, j, t}-M C_{i, t} I_{[j \neq J+1]}+\beta E\left[\log \left(\sum_{k=0}^{J+1} \exp \left(v_{k}^{M C}\left(s_{i, t+1}, h_{i, t+1}\right)\right)\right) \mid s_{i, t}, d_{i, t}=j\right]
$$

where

$$
\log \left(\sum_{k=1}^{J+1} \exp \left(v_{k}^{M C}\left(s_{i, t}, h_{i, t}\right)\right)\right)=E_{\epsilon}\left[V\left(s_{i, t}, h_{i, t}, \epsilon_{i, t}\right)\right]=E_{\epsilon}\left[\max _{k}\left[v_{k}^{M C}\left(s_{i, t}, h_{i, t}\right)+\epsilon_{i, k, t}\right]\right]
$$

Similarly to per-period utility, we break out the full choice-specific value function into a component capturing the lifetime expected utility of choosing neighborhood $j$ ignoring moving costs and another component that involves moving costs. It is worth noting that the component of lifetime utility that ignores moving costs is not a function of $h_{i, t}$, the neighborhood in which the household lives before making the decision in period $t$. Thus

$$
\begin{aligned}
v_{j}^{M C}\left(s_{i, t}, h_{i, t}\right) & =v_{j}\left(s_{i, t}\right)-M C\left(Z_{i, t}, X_{d_{i, t-1} t}\right) I_{[j \neq J+1]} \\
v_{j}\left(s_{i, t}\right) & =u_{i, j, t}+\beta E\left[\log \left(\sum_{k=0}^{J} \exp \left(v_{k}^{M C}\left(s_{i, t+1}, h_{i, t+1}\right)\right)\right) \mid s_{i, t}, d_{i, t}=j\right]
\end{aligned}
$$

\section{Estimation}

The estimation of the model primitives proceeds in four stages. In the first stage, we recover a normalized value of the non-moving cost component of lifetime expected utility for each neighborhood, time period, and observable household type, where

\footnotetext{
${ }^{28}$ In the estimation section, we will outline in detail our assumptions about the transitions of the observable states.
} 
household type is characterized by race, income, and wealth. In the second stage, we recover moving costs along with an estimate of the marginal value of wealth; the latter allows us to link the normalized values recovered in the first stage across households with different wealth levels. We use a novel approach to estimate the marginal value of wealth in this second stage, utilizing outside information relating to the financial cost of moving. In the third stage, we recover fully flexible estimates of the per-period utility. And, with estimates of the per-period utility function in hand, we regress them on a set of observable attributes in the fourth stage. As will become clear, an important feature of our estimation strategy is its low computational burden.

\subsection{Estimation Stage One - Choice-Specific Value Function}

Consider the problem faced by a household that has chosen to move. It will choose a neighborhood which offers the highest lifetime utility by maximizing over the set of choice-specific value functions $v^{M C}$. Conditional on moving, the moving cost term, $M C\left(Z_{i, t}, d_{i, t-1}\right)$, is assumed to be identical for all neighborhoods. As an additive constant, it simply drops out and, conditional on moving, each household chooses $j$ to maximize $v_{j}\left(s_{i, t}\right)+\epsilon_{i, j, t}$, where $v_{j}\left(s_{i, t}\right)$ is given in $(7)$.

We have assumed that the idiosyncratic error term, $\epsilon_{i, j, t}$, is distributed i.i.d., Type 1 Extreme Value, which allows us to recover $v_{j}\left(s_{i, t}\right)$ in a number of ways. Previous methods for estimating dynamic discrete choice models in the presence of a large choice set are plagued by a curse of dimensionality. We therefore employ a variant of Hotz and Miller (1993) based on the contraction mapping in Berry (1994), which avoids this problem. Specifically, based on household characteristics such as income, wealth, and race, we divide households into distinct types indexed by $\tau$. Let $v_{j, t}^{\tau}=v_{j}\left(s_{i, t}\right)$ when the characteristics $\left(Z_{i, t}\right)$ of the household $i$ imply that the household is of type $\tau$. $v_{j, t}^{\tau}$ is then a choice-specific value a household of type $\tau$

receives from choosing neighborhood $j$, ignoring any potential moving costs. Letting $u_{j, t}^{\tau}$ denote the deterministic component of flow utility for a household of type $\tau$, we 
can rewrite $(7)$ using lifetime utilities, $v_{j, t}^{\tau}$ :

$$
v_{j, t}^{\tau}=u_{j, t}^{\tau}+\beta E\left[\log \left(\sum_{k=0}^{J+1} \exp \left(v_{k, t+1}^{\tau_{t+1}}-M C_{j, t+1}^{\tau_{t+1}} I_{[k \neq J+1]}\right)\right) \mid s_{i, t}, d_{i, t}=j\right]
$$

We assume that agents use the state variables in $s$ and the decision $d_{i, t}$ to directly predict future lifetime utilities, $v_{j, t+1}$ and future types, $\tau_{t+1}$. We discuss exactly how they forecast in Section 4.3. Household $i$ of type $\tau$ chooses choice $j$ if $v_{j, t}^{\tau}+\epsilon_{i, j, t}>$ $v_{k, t}^{\tau}+\epsilon_{i, k, t}, \forall k \neq j$. Conditional upon moving (i.e., for $d_{i, t} \neq J+1$ ), the probability of any household of type $\tau$ choosing neighborhood $j$ in period $t$ when $\epsilon_{i, j, t}$ is distributed i.i.d., Type 1 Extreme Value can therefore be expressed as:

$$
P_{j, t}^{\tau}\left(v_{t}^{\tau}\right)=\frac{e^{v_{j, t}^{\tau}}}{\sum_{k=0}^{J} e^{v_{k, t}^{\tau}}}
$$

For any given time period, the vector of mean lifetime utilities, $v_{t}^{\tau}$, is unique up to an additive constant, thus requiring some normalization for each $\tau$. Therefore, instead of recovering $v_{j, t}^{\tau}$ for every neighborhood and type, we recover $\tilde{v}_{j, t}^{\tau}$, where $\tilde{v}_{j, t}^{\tau}=v_{j, t}^{\tau}-m_{t}^{\tau}$ and $m_{t}^{\tau}$ is a normalizing constant, a portion of which will be estimated later in the second step of our estimation procedure. Let $\hat{P}_{j, t}^{\tau}$ denote the estimated probability that households of type $\tau$ choose neighborhood $j$ in period $t$. We can then easily calculate $\tilde{v}_{j, t}^{\tau}$ as:

$$
\tilde{v}_{j, t}^{\tau}=\log \left(\hat{P}_{j, t}^{\tau}\right)-\frac{1}{J+1} \sum_{k=0}^{J} \log \left(\hat{P}_{k, t}^{\tau}\right)
$$

As the number of types, $M$, grows large relative to the sample size, we may face some small sample issues with observed shares. Therefore, instead of simply calculating observed shares as the portion of households of a given type who live in an area, we use a weighted measure to avoid zero shares. We do this to incorporate the information from similar types when calculating shares for any particular type. For example, if we want to calculate the share of households with an income of 
$\$ 50,000$ choosing neighborhood $j$ in period $t$, we would use some information about the residential decisions of those earning $\$ 45,000$ or $\$ 55,000$ in that period. Naturally, the weights will depend on how far away the other types are in type space. Denoting the weights by $W^{\tau}\left(Z_{i, t}\right)$, the formula for calculating observed shares (of inside choices) is given $b^{29}$

$$
\hat{P}_{j, t}^{\tau}=\frac{\sum_{i=1}^{N} I_{\left[d_{i, t}=j\right]} \cdot W^{\tau}\left(Z_{i, t}\right)}{\sum_{i=1}^{N} W^{\tau}\left(Z_{i, t}\right)}
$$

where the weights are constructed as the product of $K$ kernel weights, where $K$ is the dimension of $Z$. Each individual kernel weight is formed using a standard normal kernel, $N$, and bandwidth, $b_{k}$, determined by visual inspection:

$$
W^{\tau}\left(Z_{i, t}\right)=\prod_{k=1}^{K} \frac{1}{b_{k}} N\left(\frac{Z_{i, t}-Z^{\tau}}{b_{k}}\right)
$$

We also want to include a lifetime utility term for an outside option. Our data allow us to follow individuals through time, which means that we can calculate $\hat{P}_{0 t}^{\tau}$, the probability (in each year) that a seller does not buy in the Bay Area. On this basis, the inside option shares are calculated as the share of those who are buying (regardless of whether they were previously renting/owning/living in another city) and who choose neighborhood $j$. The outside option shares are calculated as the share of those who were owning in the Bay Area, sell, and then choose to not buy another house in the Bay Area. ${ }^{30}$

We use this procedure in combination with the estimated probabilities of choosing the inside options to obtain a normalized lifetime utility of choosing the outside options for each type. We denote this lifetime utility as $\tilde{v}_{0}^{\tau}$ and include it in the set of alternatives used in estimating the move/stay decision.

\footnotetext{
${ }^{29}$ If $W^{\tau}\left(Z_{i}\right)=I_{\left[Z_{i}=Z^{\tau}\right]}$, this results in the simple cells estimator for calculating shares/probabilities.

${ }^{30}$ As there are fewer observations for households that we can follow over time, we do not estimate the outside option shares separately for each year and type. Instead, we include a linear time trend that is different for each type.
} 


\subsection{Estimation Stage Two - Moving Costs and the Marginal Utility of Wealth}

In a housing market context, households behave dynamically by taking into account the effect their current decision has on future utility flows. In our model, the current decision affects future utility flows through the two channels mentioned previously - households are aware that they will incur a transaction cost by re-optimizing in the future, and in addition, the decision where to live today affects wealth in future. Equation (8) shows how the current decision affects both today's flow utility and future utility. It also suggests that if $v_{j, t}^{\tau}\left(\right.$ or $\left.\tilde{v}_{j, t}^{\tau}\right)$ is known for all $\tau$ and $j$, then we can estimate moving costs based on households' decisions to move or stay in a particular period.

Given that we recover estimates of $\tilde{v}_{j, t}^{\tau}$ from the first stage, we estimate moving costs in stage two by considering the move/stay decisions of households in the following way: From the model outlined above, we know that in any given period, a household will move if the lifetime expected utility of staying in their current neighborhood is less than the lifetime expected utility of the best other alternative when

moving costs are factored in. We assume that moving costs, $M C_{j, t}^{\tau_{t}}$, are made up of two components: financial costs, $F M C\left(h_{i, t}\right)$, and psychological costs, $P M C\left(Z_{i, t}\right)$. The financial moving costs are a function of previous location decisions, $h_{i, t}$, as households pay financial costs based primarily on the property they sell. The psychological costs are a function of the observable characteristics, $Z_{i, t}$, that define type $\tau$.

As the financial moving costs reduce wealth, choosing to move changes a household's type. For example, if moving costs are $\$ 10,000$, then a given household with $\$ 100,000$ in wealth chooses where to live based on the utility of staying in their current neighborhood with wealth of $\$ 100,000$ and the highest alternative utility with a wealth of $\$ 90,000$. In practice, we treat financial moving costs as observable and set them equal to 6 percent of the value of housing in the neighborhood that a household is leaving (i.e., $F M C\left(h_{i, t}\right)=0.06 \cdot$ Price $\left._{h_{i, t}}\right)$. 
If a household of type $\tau$ moves, we denote their new type as $\bar{\tau}$, the new type following a move reflecting the reduction in wealth by the amount of $F M C$. A household will choose to stay (not move) if:

$$
v_{J+1, t}^{\tau}+\epsilon_{i, J+1, t}>\max _{k}\left[v_{k, t}^{\bar{\tau}}+\epsilon_{i, k, t}\right]-P M C\left(Z_{i, t}\right)
$$

However, from the first stage we only recover the normalized choice-specific value functions, $\tilde{v}_{j}^{\tau}$, where $\tilde{v}_{j}^{\tau}=v_{j}^{\tau}-m^{\tau}$. We can then rewrite (13) as:

$$
\tilde{v}_{J+1, t}^{\tau}+\epsilon_{i, J+1, t}>\max _{k}\left[\tilde{v}_{k, t}^{\bar{\tau}}+\epsilon_{i, k, t}\right]-\left(m_{t}^{\tau}-m_{t}^{\bar{\tau}}\right)-P M C\left(Z_{i, t}\right)
$$

The term $\left(m_{t}^{\tau}-m_{t}^{\bar{\tau}}\right)$ is unobserved but can be estimated as the difference between the value associated with being type $\tau$ and the value associated with the reduced wealth after paying financial moving costs. In principle, we could estimate a separate term for each combination of $\tau$ and $F M C$; In parctice, we choose to parameterize it as a function of $Z_{i, t}$ and $F M C_{i, t}$, so:

$$
m_{t}^{\tau}-m_{t}^{\bar{\tau}}=F M C_{i, t} \gamma_{f m c}^{\tau}
$$

where $F M C_{i, t}=0.06 \cdot$ Price $_{h_{i, t}}$ and $\gamma_{f m c}^{\tau}=Z_{i, t}^{\prime} \gamma_{f m c}$. We parameterize the psychological costs as:

$$
P M C_{i, t}=Z_{i, t}^{\prime} \gamma_{p m c}
$$

Note that the stochastic terms are $\max _{k \neq j}\left[\tilde{v}_{k, t}^{\bar{\tau}}+\epsilon_{i, k, t}\right]$, and $\epsilon_{i, J+1, t} \cdot{ }^{31}$ We estimate $\left(m_{t}^{\tau}-m_{t}^{\bar{\tau}}\right)$ and $P M C_{i, t}$ from a likelihood function based on the probability of a household staying in its current house, where

$$
P_{i, t}^{\tau}(\text { Stay })=\frac{e^{\tilde{v}_{v+1, t}^{\tau}}}{e^{\tilde{v}_{J+1, t}^{\tau}+\sum_{k=0}^{J} e^{\tilde{v}_{k, t}^{\tilde{\tau}}-F M C_{i, t} \gamma_{f m c}^{\tau}-Z_{i, t}^{\prime} \gamma_{p m c}}}}
$$

\footnotetext{
${ }^{31}$ It would be straightforward to also allow for a shock to moving costs, which would effectively allow all the idiosyncratic errors except $\epsilon_{J+1}$ to be correlated.
} 
We then use equation (15) to form a likelihood equation consisting of every household's move/stay decision in every period. ${ }^{32}$ Maximizing this likelihood yields estimates of $\gamma_{f m c}$ and $\gamma_{p m c}$.

The earlier (first) stage of our estimation approach involved making a normalization for each type of household, where 'type' could be defined by personal characteristics such as race, income, and wealth. Once we set the mean choice-specific utility from having no wealth to zero, we only need to know these baseline differences, $m_{t}^{\tau}-m_{t}^{\bar{\tau}}$, in order to recover the unnormalized choice-specific value functions. ${ }^{33} \mathrm{As}$ we can estimate the baseline differences, we simply recover the true choice-specific value functions as $v_{j, t}^{\tau}=\tilde{v}_{j, t}^{\tau}+m_{t}^{\tau}$.

It is important to recover these baseline differences because they represent the additional utility a household would receive from extra wealth, the marginal utility of wealth being a key output of the estimation. Given that the choice of neighborhood affects future household type, the baseline differences in utility across types represent potential future utility gains from wealth accumulation. In addition, we will also use the estimate of the marginal value of wealth from this second stage as a novel way to deal with the endogeneity of house prices in the fourth stage.

\subsection{Estimation Stage Three - Per-Period Utility}

From stages one and two, we know the distribution of moving costs for each type, the marginal value of changing type, and the true mean utility terms, $v_{j}^{\tau}$. The next step is to specify and estimate the relevant transition probabilities.

We assume that households use today's states to directly predict future values of the lifetime utilities, $v$, rather than predicting the values of the variables upon which $v$ depends. As potential future moving costs are a function of the price of housing in

\footnotetext{
${ }^{32}$ We assign each household a value, $\tilde{v}_{j, t}^{\tau}$, based on which type they are closest to. Alternatively, we could estimate equation (15) separately for each type using weights similar to those in Stage 1.

${ }^{33}$ We set the mean choice-specific utility from no wealth to zero for each year/income/race combination. However, we are not imposing that these values are identically zero and effectively undo this temporary normalization through the use of year*type dummies in Stage 4.
} 
the neighborhood chosen in this period, households also need to predict how the price of the house they currently occupy will transition. Further, as both moving costs and lifetime utilities are determined by household type, households need to predict how their types will change. The only determinant of type that changes endogenously is wealth, so we assume that knowing how house prices transition is sufficient for knowing how wealth (and therefore type) will transition. ${ }^{34}$ We therefore only need to model transition probabilities for $v$ and price.

In theory, we could estimate the transition probabilities for lifetime utility separately by type, as we have a time series for each type and neighborhood. However, to increase the efficiency of our estimates, we impose some restrictions. Within each type, we could assume that the neighborhood mean utilities, $v_{j, t}^{\tau}$, evolve according to an auto-regressive process, where some of the coefficients are common across neighborhoods. In practice, we estimate transition probabilities separately for each type but pool information over neighborhoods. To account for different means and trends, we include a separate constant and time trend for each neighborhood's choice-specific value function for each type. We model the transition of the choice-specific value functions, $v_{j, t}^{\tau}$, as:

$$
v_{j, t}^{\tau}=\rho_{0, j}^{\tau}+\sum_{l=1}^{L} \rho_{1, l}^{\tau} v_{j, t-l}^{\tau}+\sum_{l=1}^{L} X_{j, t-l}^{\prime} \rho_{2, l}^{\tau}+\rho_{3, j}^{\tau} t+\omega_{j, t}^{\tau}
$$

where the time-varying neighborhood attributes included in $X_{j, t}$ are price, racial composition (percentage white), pollution (the number of days that the ozone concentration exceeds the California state maximum threshold), and the violent crime rate. $^{35}$ Lagged value functions are also included as explanatory variables, implicitly allowing the transition probabilities be a function of the unobserved neighborhood attributes.

\footnotetext{
${ }^{34}$ With access to richer data on other forms of household wealth, the definition of wealth that we use to define type could be expanded.

${ }^{35}$ For the outside option, we do not observe any attributes and estimate with only lags of the choice-specific value function. That is, we estimate $v_{0 t}^{\tau}=\rho_{0,0}^{\tau}+\sum_{l=1}^{L} \rho_{1, l}^{\tau} v_{0 t-l}^{\tau}+\rho_{3,0}^{\tau} t+v_{0 t}^{\tau}$.
} 
We also need to know how housing wealth transitions in order to specify transition probabilities for types. We use sales data to construct price indexes for each typetract-year combination. Recalling that price is one of the variables in the neighborhood characteristics $X$, we estimate transition probabilities for price levels according to:

$$
\text { price }_{j, t}=\varrho_{0, j}+\sum_{l=1}^{L} X_{j, t-l}^{\prime} \varrho_{2, l}+\varrho_{3, j} t+\varpi_{j, t}^{\tau}
$$

Given these transition probabilities, it is straightforward to estimate transition probabilities for wealth and thus type, $\tau$. In both cases, we use two lags of the dependent variable $\left(v_{j, t}^{\tau}\right.$ or $\left.\operatorname{price}_{j, t}^{\tau}\right)$ as well as two lags of the other exogenous variables in $X$.

Knowing $v, P M C$, and the transition probabilities allows us to calculate mean flow utilities for each type and neighborhood, $u_{j, t}^{\tau}$, according to:

$$
u_{j, t}^{\tau}=v_{j, t}^{\tau}-\beta E\left[\log \left(\sum_{k=0}^{J+1} \exp \left(v_{k, t+1}^{\tau_{t+1}}-M C_{j, t+1}^{\tau_{t+1}} I_{[k \neq J+1]}\right)\right) \mid s_{i, t}, d_{i, t}=j\right]
$$

where in practice, $s$ includes all the variables on the right hand side of equations (16) and (17) and $\beta$ is set equal to 0.95 .

For each type, $\tau$, neighborhood, $j$, and time, $t$, we now have the necessary information to simulate the expectation on the right hand side of (18). To do this, we draw a large number of $v_{t+1}$ 's and price $_{t+1}$ 's according to their estimated distributions. Specifically, using $r$ to index random draws, each $v_{t+1}(r)$ and $\operatorname{price}_{t+1}(r)$ are generated by drawing from the empirical distribution of errors obtained when estimating (16) and (17) and using the observed values of the current states. The draws on price $_{t+1}$ are used to form $\tau_{t+1}$ and $M C_{j, t+1}^{\tau_{t+1}} \cdot{ }^{36}$ For each draw, $r$, we can then calculate a per-period flow utility $u_{j, t}^{\tau}(r)$ using (18). The simulated $u_{j, t}^{\tau}$ is then calculated as $\frac{1}{R} \sum_{r=1}^{R} u_{j, t}^{\tau}(r) .{ }^{37}$

\footnotetext{
${ }^{36}$ Once we draw a value for price $_{t+1}$, we can calculate wealt $_{t+1}$ for someone living neighborhood $j$ as wealth $_{t}+\left(\right.$ price $_{j, t+1}-$ price $\left._{j, t}\right)$ and $M C_{j, t+1}^{\tau_{t+1}}$ as 6 percent of price $_{t+1}$.

${ }^{37}$ The total number of draws, $R$, is chosen to be large enough such that the simulated $u_{j, t}^{\tau}$ does not change as $R$ increases. In practice, setting $R$ equal to 750 is sufficient.
} 


\subsection{Estimation Stage Four - Decomposing Per-Period Utility}

Once we recover the mean per-period flow utilities, we can decompose them into functions of the observable neighborhood characteristics, $X_{j, t}$. We treat $\xi_{j, t}^{\tau}$ as an error term in the following regression:

$$
u_{j, t}^{\tau}=\alpha_{0}^{\tau}+\alpha_{c}^{\tau}+\alpha_{t}^{\tau}+X_{j, t}^{\prime} \alpha_{x}^{\tau}+\xi_{j, t}^{\tau}
$$

This decomposition of the mean flow utilities is similar to Berry, Levinsohn, and Pakes (1995) or Bayer, Ferreira, and McMillan (2007), though in these models, the choicespecific unobservable, $\xi_{j, t}$, was treated as a vertical characteristic that affected all households' utility in the same way. In our application, we allow households who are different (based on observable demographic characteristics) to view the unobservable component differently, as in Timmins (2007) - hence the $\tau$ superscript on $\xi_{j, t}^{\tau}$. The time-varying characteristics used in our application are the user cost of housing, ground-level ozone (measured in days exceeding the state standard), violent crime (measured in incidents per 100,000 residents), and a measure of racial composition (percentage white). In addition to neighborhood characteristics, we include controls for type $(\tau)$, county $(c)$, and year $(t)$.

The user cost of owning a house is typically calculated as a percentage of house value. Here, we calculate the neighborhood user cost as 5 percent of mean prices in the neighborhood. User costs are, however, clearly endogenous. The traditional approach to this problem makes use of instrumental variables. Our approach is different: we use the marginal value of wealth estimated in Section 4.2 to recover the marginal disutility of user costs. We assume that the effect of a marginal change in wealth on lifetime utility is the same as the effect of a marginal change in income on one period's utility. In particular, the marginal utility of income (the negative of which can be interpreted as the coefficient on user cost) is given by $\gamma_{f m c}^{\tau}$. To decompose mean flow

utilities, we therefore estimate the following regression, where $\widehat{\gamma_{f m c}^{\tau}}$ is known from 
Stage 2 and $\tilde{X}$ denotes the non-user cost components of $X$ :

$$
u_{j, t}^{\tau}+\widehat{\gamma_{f m c}^{\tau}} u \operatorname{sercost} t_{j, t}=\alpha_{0}^{\tau}+\alpha_{c}^{\tau}+\alpha_{t}^{\tau}+\tilde{X}_{j, t}^{\prime} \alpha_{x}^{\tau}+\xi_{j, t}^{\tau}
$$

In principle, we could decompose the flow utilities separately for each type, $\tau$, as written above. In practice, we constrain some coefficients to be the same across types and estimate several different versions of equation (20).

\section{Results}

We can estimate the model separately for any given time-invariant observable household characteristic. ${ }^{38}$ The results we report here are based on estimating the model for three income types - $\$ 40,000, \$ 120,000$, and $\$ 200,000$ - and for whites only. ${ }^{39}$ In total, we have 75 types: 25 wealth types measured in $\$ 10,000$ increments - $\$ 0$ to $\$ 240,000$ - interacted with the three income types.

While there are four stages of estimation, the primary results of interest are the marginal willingness to pay estimates recovered in the final stage. Given our approach to controlling for the endogeneity of user cost makes use of estimates of the marginal utility of wealth, we also include a brief discussion of the Stage 2 results.

\subsection{Moving Costs and the Marginal Utility of Wealth}

We use the binary move/stay decision faced by each household in every period to identify and estimate the psychological and financial components of moving costs; using the fact that financial moving costs are 6 percent of the selling price allows us to recover the marginal value of wealth also. The results of this estimation are given

\footnotetext{
${ }^{38}$ As a household's wealth transitions endogenously, the estimation requires that we include many categories of wealth.

${ }^{39}$ The process could be easily replicated for other racial groups, although small-number problems may be more of an issue in the first stage for other races. This could be addressed by pooling racial groups, at least where researchers were not seeking to estimate the value of racial composition by racial group.
} 
in Table 2. From the table, it is clear that the psychological costs of moving are large, they decrease slightly in household income, and are falling over time. ${ }^{40}$

Table 2: Moving Cost Estimates

\begin{tabular}{lr}
\hline \hline Psychological Costs & \\
Constant & 9.6040 \\
& $(0.0349)$ \\
Income & -0.0023 \\
& $(0.00025)$ \\
$t$ & -0.1092 \\
& $(0.0033)$ \\
Financial Costs & 0.0323 \\
Constant*6\% House Value & $(0.0012)$ \\
& -0.00009 \\
Income*6\% House Value & $(0.000008)$ \\
\hline
\end{tabular}

Note: Income and House Value are measured in \$1000's.

The financial cost estimates are of particular interest, given that they speak to the marginal value of wealth. These estimates suggest that the marginal value of wealth is positive but considerably lower for high-income types. The marginal per-period utility of income coefficient that we take to the estimation of Stage 4 is given by $0.0323-0.00009 *$ income. Our estimate of the marginal per-period utility of income is decreasing in income, as expected, and is roughly half as small for households with an income of $\$ 200,000$ compared to those with an income of $\$ 40,000$.

\footnotetext{
${ }^{40}$ The mean psychological costs are high are they represent the amount a household would pay to avoid moving to a randomly chosen neighborhood in a randomly chosen time period. See Kennan and Walker (2011) for an excellent discussion of the interpretation of moving costs in this class of models.
} 


\subsection{Marginal Willingness to Pay for Neighborhood Attributes}

In the process of decomposing the estimates of flow utilities in the fourth stage, we control for the endogeneity of user cost by estimating equation (20). We decompose the flow utilities in two ways. First, we pool the mean utilities for all types and restrict the preference parameters for percentage white, violent crime, and ozone (as well as the county and year effects) to be same for all households. Later, we relax these restrictions, estimating willingness to pay separately by income.

The raw coefficients resulting from this process are difficult to interpret by themselves. Therefore, to better understand the magnitude of the coefficients, we calculate per-period willingness to pay for changes in each neighborhood characteristic. Perperiod marginal willingness to pay (in $\$ 1000$ 's) is given by $\alpha_{x}^{\tau} / \gamma_{f m c}^{\tau}$, which measures how much a household would be willing to pay annually to receive a small change in each of the amenities, holding expectations about future amenities constant.

Table 3 reports willingness-to-pay (WTP) measures for a 10-percent change in each amenity across four different specifications, the WTP figures being given at the means of percent white (69.34), violent crime rate (458.62), and ozone (2.19). As the marginal utility of income, $\gamma_{f m c}^{\tau}$, varies by income, we report the willingness to pay measures for a household with income of $\$ 120,000$, which is close to the mean.

Our preferred specification is reported in column I. In this specification, we exclude the two highest and two lowest wealth categories and use a Least Absolute Deviations (LAD) regression to limit the effect of outliers. The results show that households with income of $\$ 120,000$ are willing to spend $\$ 1,558.20$ per year to increase percentage white by ten percent at the mean. The estimates are very precise. ${ }^{41}$ Analogously,

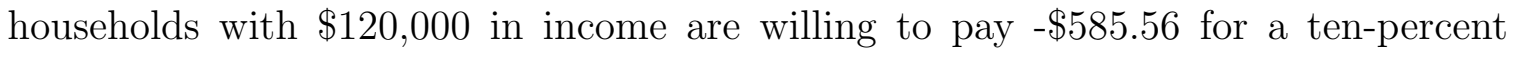
increase in violent crime. ${ }^{42}$ For ozone, households are willing to pay $-\$ 295.60$ for

\footnotetext{
${ }^{41}$ All the standard errors reported here and elsewhere in the paper were obtained using a bootstrap procedure with 125 draws.

${ }^{42}$ This willingness to pay implies a value of a statistical case of violent crime (similar in construction to the familiar value of a statistical life) of $\$ 1.2$ million. This amount is consistent with other research on the costs of crime (Linden and Rockoff (2008)) and is reasonable in magnitude (i.e., approximately
} 
a ten-percent increase in the number of days ozone exceeds the threshold. ${ }^{43}$ To shed light on the robustness of these WTP estimates, we also estimate the model using OLS instead of LAD in column II: the results there are quite similar, though WTP for percent white increases somewhat. In columns III and IV, we estimate the model without excluding the two highest and two lowest wealth categories using LAD and OLS regressions, respectively. As can be seen from the table, the results are reasonably similar to those in column I.

Table 3: Willingness to Pay for a 10-Percent Increase in Amenities

\begin{tabular}{lrrrr}
\hline \hline & \multicolumn{1}{c}{ I } & \multicolumn{1}{c}{ II } & \multicolumn{1}{c}{ III } & \multicolumn{1}{c}{ IV } \\
\hline Percent White & 1558.20 & 1952.87 & 1735.40 & 2270.88 \\
& $(42.11)$ & $(52.78)$ & $(46.90)$ & $(61.37)$ \\
Violent Crime & -585.56 & -563.69 & -603.82 & -615.97 \\
& $(15.82)$ & $(15.23)$ & $(16.32)$ & $(16.65)$ \\
Ozone & -295.60 & -329.31 & -286.83 & -319.76 \\
& $(7.99)$ & $(8.90)$ & $(7.75)$ & $(8.64)$ \\
County Dummies & Yes & Yes & Yes & Yes \\
Year Dummies & Yes & Yes & Yes & Yes \\
Type Dummies & Yes & Yes & Yes & Yes \\
Estimator & LAD & OLS & LAD & OLS \\
Wealth Outliers & NO & NO & YES & YES \\
\hline
\end{tabular}

As a supplement to the pooled estimates in Table 3, we also estimate the willingnessto-pay measures separately for each of the three income types: $\$ 40,000, \$ 120,000$, and $\$ 200,000$. The results are presented in Table 4 and point to significant heterogeneity in willingness to pay for neighborhood amenities by income. For ease of exposition, we only show results for our preferred specification - i.e., using median regression and excluding the extreme wealth types.

The implied income elasticities of demand for neighborhood race are substantial,

\footnotetext{
$\frac{1}{6}^{\text {th }}$ the size of a typical VSL estimate).

${ }^{43}$ The corresponding willingness to pay figures for one-unit changes in the three amenities are: $\$ 224.72$ per year to increase percentage white by one percentage point, $-\$ 12.77$ for one additional violent crime per 100,000 residents, and $-\$ 1,349.77$ for one extra day of ozone exceeding the threshold.
} 
with a five-fold increase in income raising WTP for percent white almost seven fold. Similarly for crime, a five-fold increase in income is estimated to increase WTP slightly more than four fold. In contrast, the implied income elasticities of demand for ozone are much smaller, with a five fold increase in income only increasing WTP to avoid ozone by 27 percent. ${ }^{44}$

Table 4: Willingness to Pay for a 10-Percent Increase in Amenities by Income

\begin{tabular}{lrrr}
\hline \hline & $\$ 40,000$ & $\$ 120,000$ & $\$ 200,000$ \\
\hline Percent White & 585.35 & 1342.87 & 3932.49 \\
& $(18.36)$ & $(36.29)$ & $(207.86)$ \\
Violent Crime & -327.38 & -572.33 & -1341.25 \\
& $(10.27)$ & $(15.47)$ & $(70.89)$ \\
Ozone & -274.62 & -292.67 & -347.79 \\
& $(8.61)$ & $(7.91)$ & $(18.38)$ \\
\hline
\end{tabular}

\section{Dynamic Versus Static Approaches}

Equation (8) illustrates the problems associated with estimating a static model when the true model is dynamic: in essence, specifying a static model creates an omitted variables problem. In a dynamic setting, current neighborhood characteristics determine the choice-specific value functions in two ways: (i) they affect flow utility directly, and (ii) they help predict future neighborhood utility. Estimating a static model omits the latter effect.

The static model can be conveniently nested within our dynamic framework. The former effectively assumes that the household will always stay in the same location and that attributes will never change; therefore, the location-specific value function remains constant over time. As such, one interpretation of the static model is that

\footnotetext{
${ }^{44}$ These results are also robust to the alternative specifications shown in Table 3 - available from the authors upon request.
} 
$v_{j, t}^{\tau}=u_{j, t}^{\tau} /(1-\beta) .{ }^{45}$ Therefore, the omitted variable can be expressed as:

$$
\beta E\left[\log \left(\sum_{k=0}^{J+1} \exp \left(v_{k, t+1}^{\tau_{t+1}}-M C_{j, t+1}^{\tau_{t+1}} I_{[k \neq J+1]}\right)\right) \mid s_{i, t}, d_{i, t}=j\right]-\beta v_{j, t}^{\tau}
$$

The specific way a given current characteristic predicts future utility will determine whether the static estimator over- or under-predicts the effect of that characteristic on per-period utility. If higher values of a given characteristic predict improvements in a neighborhood, then the marginal willingness to pay for that attribute will be biased towards positive infinity, which is the case for all three amenities we consider (public safety, air quality, and neighborhood percent white). ${ }^{46}$

To set out the relevant intuition, it is useful to think about the current value of an attribute predicting future values of that attribute, rather than future utilities. First consider a disamenity, such as violent crime, that is mean-reverting: as in our data, a high level of crime today predicts falling crime in future. In this case, we would expect the static model to understate the disutility of crime. The argument is as follows: households may be willing to pay quite large amounts to avoid high levels of crime. However, when they see a neighborhood with high values of this disamenity, they know that value is likely to fall in the future; and they are therefore willing to pay much more for a house in that 'bad' neighborhood than they would be willing to pay if the high value of the disamenity were permanent. The upshot is that the estimated willingness to pay to avoid crime taken from a naive static model will tend to be biased downward. The same type of argument applies similarly to air pollution - in our data, ozone levels are also mean-reverting.

There are other neighborhood attributes that are persistent over time, such as

\footnotetext{
${ }^{45}$ This interpretation is equivalent to setting $\beta=0$ while making the single-period price equal to the user cost. The latter is consistent with the literature: no static models of the housing market assume that the household pays the full sales price for one period's utility.

${ }^{46}$ Given that our actual measures are for crime and pollution - disamenities rather than amenities - a positive bias in the relevant coefficient means that the absolute effect of crime and pollution on utility will be biased downwards - i.e., the static results will suggest households have a weaker distaste for those disamenities.
} 
racial composition. In contrast to ozone and crime, seeing a high percentage of whites in a neighborhood today signals that the neighborhood is more likely to have an even higher percentage white in the future. If these are attributes that households value (and recall that we are only modeling the decisions of white households), they will be willing to pay more for a house in such a neighborhood than they would if the high value of the attribute were only temporary - in other words, persistent amenities are likely to be worth more than fleeting ones. A naive static model ignores this fact and attributes all of the value to current preferences, thereby overstating the contribution to flow utility of high percentage white neighborhoods for white households.

To highlight the problems associated with ignoring forward-looking behavior, we estimate a static version of our model for comparison purposes. Under the assumption that agents are not forward-looking, a fraction of Stage 1 estimates (i.e., $v_{j, t}^{\tau}(1-\beta)$ ) can be interpreted as flow utilities. We can then decompose those flow utilities by running the same Stage 4 procedure used to decompose $u_{j, t}^{\tau}$ above. In particular, we estimate equation $(20)$, replacing $u_{j, t}^{\tau}$ with $v_{j, t}^{\tau}(1-\beta)$. The marginal utility of income is recovered in Stage 2 and is still equal to $\gamma_{f m c}^{\tau}$. By using the same marginal utility of income coefficient as in our dynamic specification, we keep the models as comparable as possible and limit any bias to the coefficients on the amenities. Here, even if the researcher were to incorrectly assume the model to be static, she would control for the correlation between price and unobserved neighborhood attributes using an Instrumental Variables approach. Yet if the true model is dynamic, the chosen instrument will typically not be valid. ${ }^{47}$

Table 5 reports the marginal willingness to pay for a 10-percent change in each amenity derived from the static version of the model when we pool all types and

\footnotetext{
${ }^{47}$ The problem with the IV strategy is that if the true model is actually dynamic, any static instrument will be correlated with expected future utility, which is subsumed in the error term. In particular, a condition that any potential instrument must satisfy is that it should be correlated with the endogenous variable - in this case, price. Now, expected future utility is a function of all current attributes. Therefore, unless current price has no predictive power with respect to future utility, it will be impossible to find an instrument that is both correlated with price but also uncorrelated with expected future utility.
} 
evaluate at mean income. The dynamic results from Table 3 are also included for ease of reference. As before, the marginal willingness to pay figures are reported at the means of the amenity levels.

Table 5: Willingness to Pay for a 10-Percent Increase in Amenities - Static versus Dynamic Estimates

\begin{tabular}{lrr}
\hline \hline & Static & Dynamic \\
\hline Percent White & 1973.79 & 1558.20 \\
& $(53.34)$ & $(42.11)$ \\
Violent Crime & -343.63 & -585.56 \\
& $(9.29)$ & $(15.82)$ \\
Ozone & -73.25 & -295.60 \\
& $(1.98)$ & $(7.99)$ \\
\hline
\end{tabular}

The comparison of static and dynamic results in the table suggests that incorrectly estimating a static model in a dynamic context can lead to very biased estimates. The static model substantially overestimates willingness to pay for living in close proximity to neighbors of the same race: the static estimate is $\$ 1,973.79$ whereas the corresponding dynamic estimate is $\$ 1,558.20$. The biases for both crime and air pollution, while also large in absolute terms, run in the opposite direction. The static estimates for crime are $-\$ 343.63$ in the static case and $-\$ 585.56$ in the dynamic case respectively for a 10-percent increase in violent crime, while for pollution, the static estimates are $-\$ 73.25$ versus $-\$ 295.60$ in the dynamic case, again for a 10 -percent increase in ozone. In each case, the differences are substantial and are precisely estimated.

The signs of these biases are consistent with the discussion above - a high value of each of the three amenities predicts improvements in the respective neighborhoods. That is, the partial correlation between the three amenities and the omitted variable, as defined in equation (21), is positive, meaning that preferences for amenities will be biased upwards and preferences for disamenities will be biased downwards in absolute 
value.

From a different angle, it is also interesting to see whether these biases can be explained by patterns in the actual variables themselves. This is especially the case as the omitted variable given by the equation is only known once the full structural model has been estimated. We set out regressions exploring the time-series patterns of each (dis)amenity in Table A.3 in the Appendix. For all three amenities, the timeseries patterns are consistent with the biases found: higher percent white this period predicts larger increases (or smaller reductions) in percent white one period ahead, and higher ozone and crime rates this period predict larger falls (or smaller increases) in ozone and crime one period ahead.

It is worth emphasizing that the transition probability regressions shown in Table A.3 were not used in our estimation routine; there, we used lagged attributes to predict future value functions directly, rather than using them to predict future amenities. As we do not use the time-series patterns of the amenities directly in our estimation, we take confidence from the fact that our empirical results are consistent with these patterns.

Table 6: Willingness to Pay for a 10-Percent Increase in Amenities - Static versus Dynamic Estimates by Income

\begin{tabular}{lrrrrrr}
\hline \hline & \multicolumn{3}{c}{ Static } & \multicolumn{3}{c}{ Dynamic } \\
& $\$ 40,000$ & $\$ 120,000$ & $\$ 200,000$ & $\$ 40,000$ & $\$ 120,000$ & $\$ 200,000$ \\
\hline Percent White & 1787.62 & 2015.00 & 2551.79 & 585.35 & 1342.87 & 3932.49 \\
& $(56.06)$ & $(54.45)$ & $(134.88)$ & $(18.36)$ & $(36.29)$ & $(207.86)$ \\
Violent Crime & -268.57 & -334.62 & -475.81 & -327.38 & -572.33 & -1341.25 \\
& $(8.42)$ & $(9.04)$ & $(25.15)$ & $(10.27)$ & $(15.47)$ & $(70.89)$ \\
Ozone & -68.70 & -74.49 & -92.24 & -274.62 & -292.67 & -347.79 \\
& $(2.15)$ & $(2.01)$ & $(4.88)$ & $(8.61)$ & $(7.91)$ & $(18.38)$ \\
\hline
\end{tabular}

In Table 6, we present results from an analysis of how willingness to pay varies with income in the static model versus the dynamic model; again, we also include the earlier dynamic estimates from Table 4 for comparison. The income elasticities 
implied by the static model are substantially smaller for both race and crime relative to the elasticities from the dynamic model, apparent from the much steeper profiles in the dynamic case; for ozone, the respective elasticities are fairly similar. The static model biases are again broadly consistent with the above discussion, with the income elasticities being considerably larger in the dynamic model, at least for race and crime. For high-income households, the income elasticity of demand for race is sufficiently low in the static model that the sign of the bias for high income households changes direction. All other biases have the same sign in the model where amenity preferences vary by income type as in the pooled model. ${ }^{48}$

\section{Conclusion}

While models of residential sorting and hedonic equilibrium have a long history in economics, almost all existing empirical studies based on these models have adopted a static estimation approach. This is with good with reason: computational and data issues have made the estimation of dynamic models extraordinarily difficult. Yet location decisions are inherently dynamic, and this has led to concerns that the estimates from static models may be seriously biased.

In this paper, we developed a tractable dynamic model of neighborhood choice that controls for unobserved neighborhood heterogeneity, along with a computationally straightforward semi-parametric estimation approach. Our neighborhood choice model and estimator adapt dynamic demand models for durable and storable goods for use in a housing market context, and build on this class of models in several ways: (i) treating the house as an asset and allowing household wealth to evolve endogenously, (ii) using stable, uniform realtor fees to estimate the marginal utility of consumption without the need for a price instrument, and (iii) relaxing the strong assumption about the evolution of the continuation value that is standard in the

\footnotetext{
${ }^{48}$ The patterns described in Tables 5 and 6 are also robust to the alternative specifications shown in Table 3 - available on request.
} 
existing literature.

With our model and estimation approach in hand, we merged very rich transactions data with publicly-available mortgage application data to create a data set that matches the attributes of many buyers and sellers to homes. We then used this dynamic data set to estimate household preferences in a manner consistent with forward-looking behavior. In light of the concerns about bias when using static models, the estimates we obtained indicate that the biases associated with static demand estimation are significant for three important non-marketed amenities: air quality, crime, and neighborhood race. Further, the signs of the biases we find are consistent with what one would expect, based on the time-series properties of each amenity.

Given the importance of accounting for such dynamic considerations when estimating preferences for non-marketed goods, the model, data set, and estimation procedure presented in this paper have potentially broad applicability to the study of a range of dynamic phenomena in housing markets and cities. These include examining the microdynamics of residential segregation and gentrification within metropolitan areas - applications we intend to pursue in related research using our approach. 


\section{References}

Aguirregabiria, V., and A. Nevo (2010): "Recent Developments in Empirical Dynamic Models of Demand and Competition in Oligopoly Markets," mimeo, University of Toronto.

Bajari, P., C. L. Benkard, and J. Krainer (2005): "House Prices and Consumer Welfare," Journal of Urban Economics, 58, 474-487.

Bajari, P., And M. Kahn (2005): "Estimating Housing Demand With An Application to Explaining Racial Segregation in Cities," Journal of Business and Economic Statistics, 23(1), 20-33.

Bayer, P., F. Ferreira, and R. McMillan (2007): "A Unified Framework for Measuring Preferences for Schools and Neighborhoods," Journal of Political Economy, 115(4), 588-638.

Bayer, P., N. Keohane, and C. Timmins (2009): "Migration and Hedonic Valuation: The Case of Air Quality," Journal of Environmental Economics and Management, 58(1), 1-14.

Bayer, P., R. McMillan, and K. Rueben (2011): "An Equilibrium Model of Sorting in an Urban Housing Market," mimeo, Duke University.

Berry, S. (1994): "Estimating Discrete Choice Models of Product Differation," RAND Journal of Economics, 25, 242-262.

Berry, S., J. Levinsohn, and A. Pakes (1995): "Automobile Prices in Market Equilibrium," Econometrica, 63, 841-890.

Bishop, K. (2007): "A Dynamic Model of Location Choice and Hedonic Valuation," mimeo, Washington University in St. Louis.

Bishop, K. C., And C. Timmins (2010): "Simple, Consistent Estimation of the Marginal Willingness to Pay Function: Recovering Rosen's Second Stage Without Instrumental Variables," mimeo, Washington University in St. Louis.

Caetano, G. (2010): "Identification and Estimation of Parental Valuation of School Quality in the US," mimeo, University of Rochester.

Case, K., and R. Shiller (1989): "The Efficiency of the Market for Single-Family Homes," American Economic Review, 79(1), 125-137. 
Cragg, M., And M. Kahn (1997): "New Estimates of Climate Demand: Evidence from Location Choice," Journal of Urban Economics, 42(2), 261-284.

Ekeland, I., J. J. Heckman, and L. Nesheim (2004): "Identification and Estimation of Hedonic Models," Journal of Political Economy, 112(1), S60-S109.

Ellickson, B. (1971): "Jurisdictional Fragmentation and Residential Choice," American Economic Review, 61(2), 334-339.

Epple, D. (1987): "Hedonic Prices and Implicit Markets: Estimating Demand and Supply Functions for Differentiated Products," Journal of Political Economy, 95(1), 59-80.

Epple, D., R. Filimon, and T. Romer (1984): "Equilibrium among local jurisdictions: Toward an integrated treatment of voting and residential choice," Journal of Public Economics, 24(3), 281-308.

Epple, D., And R. Romano (1998): "Competition between private and public schools, vouchers, and peer-group effects," American Economic Review, 88(1), 3362.

Epple, D., R. Romano, and H. Sieg (2006): "Admission, Tuition, and Financial Aid Policies in the Market for Higher Education," Econometrica, 74(4), 885-928.

- (2010): "The Intergenerational Conflict over the Provision of Public Education," mimeo, Carnegie-Mellon University.

Epple, D., And T. Romer (1991): "Mobility and Redistribution," Journal of Political Economy, 99(4), 828-858.

Epple, D., And H. SiEg (1999): "Estimating Equilibrium Models of Local Jurisdictions," Journal of Political Economy, 107, 645-681.

Ferreyra, M. (2007): "Estimating the Effects of Private School Vouchers in MultiDistrict Economies," American Economic Review, 97(3), 789-817.

Gibbons, S. (2004): "The Costs of Urban Property Crime," Economic Journal, 114, F441-F463.

Hendel, I., And A. Nevo (2006): "Measuring the Implications of Sales and Consumer Inventory Behavior," Econometrica, 74(6), 1637-1673.

Hotz, V. J., And R. A. Miller (1993): "Conditional Choice Probabilities and the Estimation of Dynamic Models," Review of Economic Studies, 60, 497-529. 
Kahn, M. (1995): "A Revealed Preference Approach to Ranking City Quality of Life," Journal of Urban Economics, 38(2), 221-235.

Kennan, J., and J. R. Walker (2011): "The Effect of Expected Income on Individual Migration Decisions," Econometrica, 79(1), 211-251.

Kuminoff, N. V. (2008): "Recovering Preferences from a Dual-Market Locational Equilibrium," mimeo, Arizona State University.

Kuminoff, N. V., and A. S. Jarrah (2010): "A New Approach to Computing Hedonic Equilibria and Investigating the Properties of Locational Sorting Models," Journal of Urban Economics, 67(3), 322-335.

Linden, L., And J. Rockoff (2008): "Estimates of the Impact of Crime Risk on Property Values from Megan's Laws," American Economic Review, 98(3), 11031127.

Melnikov, O. (2001): "Demand for Differentiated Durable Products: The Case of the U.S. Computer Printer Market," mimeo.

Murphy, A. (2007): "A Dynamic Model of Housing Supply," mimeo, Washington University in St. Louis.

NechybA, T. J. (1999): "School Finance Induced Migration and Stratification Patterns: The Impact of Private School Vouchers," Journal of Public Economic Theory, 1(1), 5-50.

(2000): "Mobility, Targeting, and Private-School Vouchers," American Economic Review, 90(1), 130-146.

Ortalo-Magné, F., and S. Rady (2002): "Tenure Choice and the Riskiness of Non-Housing Consumption," Journal of Housing Economics, 11(3), 266-279.

- (2006): "Housing Market Dynamics: On the Contribution of Income Shocks and Credit Constraints," Review of Economic Studies, 73(2), 459-485.

(2008): "Heterogeneity Within Communities: A Stochastic Model with Tenure Choice," Journal of Urban Economics, 64(1), 1-17.

Rosen, S. (1974): "Hedonic Prices and Implicit Markets: Product Differentiation in Pure Competition," Journal of Political Economy, 82(1), 34-55.

Rust, J. (1987): "Optimal Replacement of GMC Bus Engines: An Empirical Model of Harold Zurcher," Econometrica, 55(5), 999-1033. 
Sieg, H., V. K. Smith, H. S. Banzhaf, and R. Walsh (2004): "Estimating the General Equilibrium Benefits of Large Changes in Spatially Delineated Public Goods," International Economic Review, 45, 1047-1077.

Timmins, C. (2007): "If You Can't Take the Heat, Get Out of the Cerrado... Recovering the Equilibrium Amenity Cost of Non-Marginal Climate Change in Brazil," Journal of Regional Science, 47(1), 1-25.

Walsh, R. (2007): "Endogenous Open Space Amenities in a Locational Equilibrium," Journal of Urban Economics, 61(2), 319-344. 


\section{Appendix}

Table A.1: Comparison of Sample Statistics for Merged Data and IPUMS Data by Bay Area County

\begin{tabular}{|c|c|c|c|c|c|c|}
\hline & ALAM & C.C. & MARIN & S.F. & S.M. & S.C. \\
\hline \multicolumn{7}{|c|}{ HMDA / Transactions Data } \\
\hline Median Income & 83000 & 78000 & 121000 & 103000 & 108000 & 101000 \\
\hline Mean Income & 98977 & 99141 & 166220 & 147019 & 137777 & 123138 \\
\hline Std Dev Income & 96319 & 97928 & 176660 & 225646 & 123762 & 125138 \\
\hline \multicolumn{7}{|c|}{ IPUMS } \\
\hline Median Income & 83400 & 76785 & 120000 & 100000 & 102400 & 100000 \\
\hline Mean Income & 104167 & 99047 & 162322 & 137555 & 140447 & 124483 \\
\hline Std Dev Income & 84823 & 83932 & 138329 & 121552 & 123451 & 99373 \\
\hline \multicolumn{7}{|c|}{ HMDA / Transactions Data } \\
\hline Percent White & 49.85 & 68.27 & 90.65 & 59.12 & 60.08 & 49.07 \\
\hline Percent Asian & 28.68 & 10.55 & 4.68 & 31.47 & 26.57 & 34.21 \\
\hline Percent Black & 6.45 & 6.01 & 0.67 & 2.08 & 1.22 & 1.45 \\
\hline Percent Hispanic & 11.76 & 12.38 & 2.51 & 5.86 & 9.90 & 12.27 \\
\hline \multicolumn{7}{|c|}{ IPUMS } \\
\hline Percent White & 47.64 & 64.57 & 87.5 & 61.92 & 58.1 & 50 \\
\hline Percent Asian & 27.34 & 11.37 & 3.3 & 23.37 & 25.41 & 33.51 \\
\hline Percent Black & 7.77 & 6.05 & 2.3 & 2.8 & 1.24 & 1.16 \\
\hline Percent Hispanic & 14.62 & 14.2 & 3.62 & 8.18 & 12.5 & 12.09 \\
\hline
\end{tabular}


Table A.2: Comparison of Sample Statistics for Transactions Data and Merged Data Transactions Data

\begin{tabular}{llllll}
\hline \hline Variable & Obs. & Mean & Std. Dev. & Min. & Max. \\
\hline Sale Price & 1045920 & 354915 & 220886 & 16500 & 1521333 \\
Lot Size & 1045920 & 6857 & 11197 & 0 & 199940 \\
Square Footage & 1045920 & 1647 & 714 & 400 & 10000 \\
Number Bedrooms & 1045920 & 2.98 & 1.10 & 0 & 8 \\
Number Rooms & 1045920 & 6.73 & 2.00 & 1 & 18
\end{tabular}

Merged HMDA/Transactions Data

\begin{tabular}{llllll}
\hline \hline Variable & Obs. & Mean & Std. Dev. & Min. & Max. \\
\hline Sale Price & 804699 & 372240 & 212938 & 16513 & 1521204 \\
Lot Size & 804699 & 6730 & 10605 & 0 & 199940 \\
Square Footage & 804699 & 1649 & 687 & 400 & 10000 \\
Number Bedrooms & 804699 & 3.01 & 1.08 & 0 & 8 \\
Number Rooms & 804699 & 6.77 & 1.98 & 1 & 18 \\
\hline
\end{tabular}

Table A.3: Time-Series Properties of Amenities

\begin{tabular}{lrrr}
\hline \hline & $\Delta$ Percent White $_{t+1}$ & $\Delta$ Violent Crime $_{t+1}$ & $\Delta$ Ozone $_{t+1}$ \\
\hline Percent White $_{t}$ & 0.0162 & -0.3736 & 0.0097 \\
& $(0.0002)$ & $(0.0138)$ & $(0.0003)$ \\
Violent Crime $_{t}$ & 0.0010 & -0.1605 & -0.0010 \\
& $(0.00001)$ & $(0.0010)$ & $(0.00002)$ \\
Ozone $_{t}$ & -0.01185 & -1.2256 & -0.6578 \\
& $(0.0014)$ & $(0.1034)$ & $(0.0021)$ \\
County Dummies & Yes & Yes & Yes \\
Year Dummies & Yes & Yes & Yes \\
\hline
\end{tabular}

Note: For the dependent variable, $\Delta X_{t+1}=X_{t+1}-X_{t}$. 